\title{
A Study of the Age of Menopause and Menopausal Symptoms among Women in a Rural Area of Tamil Nadu, India
}

\author{
${ }^{1} \mathrm{G}$ Ganitha, ${ }^{2}$ PB Premalatha, ${ }^{3}$ Iyanar Kannan
}

\begin{abstract}
Aim: The aim of this study is to determine the age and symptoms of menopause, and attitude and perception of postmenopausal women toward menopause in a rural area of Tamil Nadu.
\end{abstract}

Materials and methods: This is a cross-sectional observational study of 500 women in a rural area of Tamil Nadu. Women aged 40 to 55 years who had attained natural menopause and had cessation of menses for at least 1 year were included in the study. Women who had attained surgical menopause or menopause secondary to medical illness were excluded from the study. A self-structured questionnaire was used to collect information.

Results: The mean age of attaining menopause was $45.75 \pm$ 3.83 years; $87 \%$ women were symptomatic with at least one symptom. Majority of women $(78.2 \%)$ had psychosomatic symptoms followed by vasomotor symptoms (55.8\%); $68.4 \%$ women welcomed menopause with positive attitude; $19.4 \%$ women were indifferent and $12.2 \%$ women had negative attitude toward menopause. About $24 \%$ women felt that the symptoms of menopause were distressing; $23.2 \%$ women availed some form of treatment for their symptoms.

Conclusion: Many women are affected by menopausal symptoms. Some women are affected severely by these symptoms. Lack of awareness, economic factors, sociocultural factors, myths, and inaccessibility to health services can negatively affect the attitude of women toward menopause.

Clinical significance: Menopause is an important transitional phase of life in all women. The waning ovarian hormone level causes several symptoms, some of which can be distressing to some women. Age and symptoms of menopause are influenced by several factors. Attitude and perception of women toward menopause reflect the awareness and health care accessibility in the community. Creating awareness of menopausal symptoms can improve utilization of health services and the quality of life of postmenopausal women.

How to cite this article: Ganitha G, Premalatha PB, Kannan I. A Study of the Age of Menopause and Menopausal Symptoms among Women in a Rural Area of Tamil Nadu, India. J South Asian Feder Menopause Soc 2017;5(2):87-91.

\footnotetext{
${ }^{1,3}$ Associate Professor, ${ }^{2}$ Professor

1,2Department of Obstetrics and Gynecology, Tagore Medical College \& Hospital, Chennai, Tamil Nadu, India

${ }^{3}$ Department of Microbiology, Tagore Medical College \& Hospital Chennai, Tamil Nadu, India

Corresponding Author: G Ganitha, Associate Professor Department of Obstetrics and Gynecology, Tagore Medical College \& Hospital, Chennai, Tamil Nadu, India, Phone: +9442032623, e-mail: drgganitha77@gmail.com
}

Keywords: Menopausal symptoms, Menopause, Postmenopausal women, Psychosomatic symptoms, Vasomotor symptoms.

Source of support: Nil

Conflict of interest: None

Date of received: 22 July 2017

Date of acceptance: 9 August 2017

Date of publication: December 2017

\section{INTRODUCTION}

Menopause is the cessation of ovarian function represented by absence of menses for at least 12 months. ${ }^{1}$ During this period, the declining estrogen level causes a wide range of symptoms. There is a wide variation in the age and symptomatology of menopause among women all over the world. ${ }^{2-4}$ The mean age of natural menopause varies between 45 and 55 years. ${ }^{1}$ There is evidence of difference in the prevalence of symptoms in Asian and Western women. ${ }^{5}$ Further, variations have been found in Indian women in different regions. ${ }^{6-14}$

This study aims at analyzing the age of onset of menopause and the prevalence of menopausal symptoms in a rural area of Tamil Nadu. In this study, we also aim at knowing the attitude and perceptions of the local women. Perceptions and attitude toward menopause depend largely on awareness of symptoms and utilization of health care services. Majority of the women are unaware of menopausal symptoms and its health effects. In some women, the menopausal symptoms can be severe enough to affect their normal life. ${ }^{9,15,16}$

Studying the symptomatology and menopauserelated health issues of women in the community level gives us an insight of the unmet needs of the local women and helps us to provide focused service. This knowledge can be utilized for creating awareness and improving the quality of life of postmenopausal women. Since most of the population in India is rural, similar studies from different regions of India can be used for comparison and this information may be utilized for providing optimal health care to the rural postmenopausal women.

\section{MATERIALS AND METHODS}

This study was a community-based cross-sectional, descriptive, observational study conducted among 500 
rural women living in Kattankulathur block of Kancheepuram district in Tamil Nadu. There are 41 villages in Kattankulathur block. Institutional ethical committee clearance was obtained. Sample size was calculated using results from a pilot study on 30 women. The incidence of the commonest symptom, i.e., psychomotor symptom, was found to be $90 \%$. Accordingly, minimum sample size (with allowable error of $10 \%$ of prevalence) was 444 . For convenience, a sample size of 500 was chosen.

The study was carried out from November 2015 to June 2016. Women in the age group of 40 to 55 years who had attained natural menopause and had cessation of menses for at least 1 year were included in the study. Women who attained surgical menopause or menopause secondary to medical illness were excluded from the study. Women who had medical or surgical disorders, e.g., diabetes, hypertension, orthopedic disorders, cancer, and psychiatric disorders, were also excluded from the study.

Study subjects were chosen by simple random sampling method. Data were collected from postmenopausal women attending general health camps, women accompanying patients attending gynecology outpatient departments (OPDs) or other OPDs. Data were also collected from house-to-house surveys. The participants were interviewed on one-to-one basis using a self-constructed semistructured questionnaire. Written informed consent was taken from each participant. The questionnaire prepared in the local language consisted of sociodemographic data, menopausal symptoms, awareness to symptoms and treatment, attitude toward menopause, and treatment availed by symptomatic women.

Descriptive statistical analysis, viz. percentage, mean, and standard deviation, was calculated. Analysis of variance (ANOVA) and chi square test were used to find the correlation between the sociodemographic characteristics and the age of menopause. All the statistical analyses were performed by Statistical Package for the Social Sciences version 20 software.

\section{RESULTS}

A total of 500 women belonging to the age group of 40 to 55 years participated in the study. The mean age of the participants was $52.01 \pm 2.99$ years. The mean age of attaining menopause was $45.75 \pm 3.83$ years. The least age of attaining menopause was 38 years and the maximum age noted was 53 years. Most women (53\%) attained menopause in the age group of 45 to 49 years. The incidence of premature menopause was $4.8 \%$.

The sociodemographic profile of the participants is described in Table 1. The sociodemographic characteristics studied included marital status, educational status, socioeconomic status (as per modified BG Prasad scale,
Table 1: Sociodemographic profile of the participants

\begin{tabular}{|c|c|c|}
\hline Sociodemographic characteristic & Frequency & Percentage \\
\hline \multicolumn{3}{|l|}{ Age (years) } \\
\hline $40-44$ & 28 & 5.6 \\
\hline $45-49$ & 102 & 20.4 \\
\hline $50-55$ & 370 & 74.0 \\
\hline \multicolumn{3}{|l|}{ Age of menopause (years) } \\
\hline$<40$ & 24 & 4.8 \\
\hline $40-44$ & 121 & 24.2 \\
\hline $45-49$ & 265 & 53.0 \\
\hline $50-55$ & 90 & 18.0 \\
\hline \multicolumn{3}{|l|}{ Marital status } \\
\hline Married & 403 & 80.6 \\
\hline Unmarried/widow/separated & 97 & 19.4 \\
\hline \multicolumn{3}{|l|}{ Literacy status } \\
\hline Illiterate & 26 & 5.2 \\
\hline School & 393 & 78.6 \\
\hline Graduate & 81 & 16.2 \\
\hline \multicolumn{3}{|l|}{ Occupation status } \\
\hline Housewife & 355 & 71.0 \\
\hline Employed & 145 & 29.0 \\
\hline \multicolumn{3}{|l|}{ Socioeconomic status } \\
\hline (I) Upper class & 0 & 0 \\
\hline (II) Upper middle class & 50 & 10.0 \\
\hline (III) Middle class & 240 & 48.0 \\
\hline (IV) Lower middle class & 210 & 42.0 \\
\hline (V) Lower class & 0 & 0 \\
\hline \multicolumn{3}{|l|}{ Parity } \\
\hline Nulliparous & 46 & 9.2 \\
\hline Primipara & 92 & 18.4 \\
\hline Multipara & 362 & 72.4 \\
\hline
\end{tabular}

2014), occupation status, and parity. ${ }^{17}$ Using ANOVA and chi square tests, we did not find any correlation between these characteristics and the age of menopause.

About $87 \%$ women were symptomatic having at least one symptom; $68.2 \%$ women gave history of menstrual irregularities prior to attaining menopause. The menstrual irregularities included decreased or heavy menstrual flow, polymenorrhea or oligomenorrhea, or a combination of these. Majority of the women (78.2\%) had psychosomatic symptoms followed by vasomotor symptoms $(55.8 \%)$. The frequency of menopausal symptoms is described in Graph 1 and Table 2.

Only 33\% of women had awareness to symptoms of menopause. Most women attributed their symptoms, in particular psychosomatic symptoms, to ageing, increased workload, or stress in family. Only $27.8 \%$ were aware that there was some form of treatment for their symptoms; $23.2 \%$ women either approached a doctor or took overthe-counter drugs or native treatment for their symptoms. None of the women were aware of hormone replacement therapy (HRT); 68.4\% women welcomed menopause with positive attitude; $19.4 \%$ women were indifferent and $12.2 \%$ women had negative attitude toward menopause. 
Study of the Age and Symptoms of Menopause

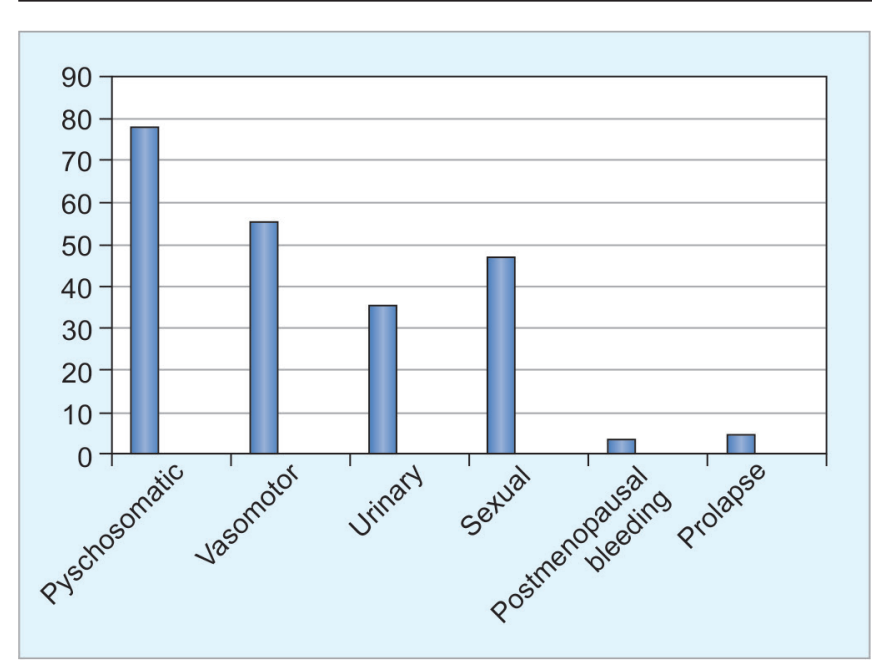

Graph 1: Frequency of menopausal symptoms. X-axis shows the percentage of frequency of menopausal symptoms. Y-axis shows menopausal symptoms

About $24 \%$ women felt that the symptoms of menopause were distressing.

\section{DISCUSSION}

The mean age of attaining menopause in our study subjects was $45.75 \pm 3.83$ years. The mean age of menopause in rural areas of India as observed in other studies ranged from $44.06 \pm 3.06$ to $48.26 \pm 4.86$ years. ${ }^{6,9-11,16,18,19}$ The age of menopause in Indian urban women is comparable and ranged from 43.94 to 47.35 years. ${ }^{12-14,20}$ Several studies show that the age of menopause among Indian women is lower than in other parts of the world. ${ }^{2-4,21,22}$ With increasing life expectancy and comparatively lower mean age at menopause, we can expect Indian women to have a longer postmenopausal period and its consequences than their counterparts worldwide.

In the present study, the incidence of premature menopause was $4.8 \%$. This is comparable to the study conducted by Dasgupta and Ray (4\%). ${ }^{14}$ In the study conducted by Singh and Pradhan, ${ }^{18}$ the incidence was lower (1.6\%).

Similar to our study, studies on Indian rural women by Avin Alva and Chethan ${ }^{6}$ and Kriplani and Banerjee ${ }^{23}$ did not find any correlation between age of menopause and education, occupation, socioeconomic status, marital status, and parity. In the present study, $87 \%$ of the postmenopausal women experienced one or more symptoms. Similar prevalence was noted in other Indian studies. $15,18,19$

We compared the frequency of menopausal symptoms in the present study with other studies on Indian rural women, Indian urban women, Asian women, and African women.

In the present study, majority of women $(78.2 \%)$ had one or more psychosomatic symptoms. Similar to our
Table 2: Frequency of menopausal symptoms

\begin{tabular}{lll}
\hline Symptom & Frequency & Percentage \\
\hline Psychosomatic & 391 & 78.2 \\
Fatigue & 339 & 67.8 \\
Muscle and joint pain & 369 & 73.8 \\
Insomnia & 217 & 43.4 \\
Low mood & 105 & 21.0 \\
Poor memory & 155 & 31.0 \\
Irritability & 211 & 42.2 \\
Lack of concentration & 161 & 32.2 \\
Vasomotor & 279 & 55.8 \\
Hot flushes & 256 & 51.2 \\
Night sweats & 221 & 44.2 \\
Headache & 182 & 36.4 \\
Palpitations & 32 & 6.4 \\
Urinary symptoms & 176 & 35.2 \\
Stress incontinence & 71 & 14.2 \\
Urgency/urge incontinence & 107 & 21.4 \\
Recurrent UTI & 66 & 13.2 \\
Frequency & 145 & 29.0 \\
Dysuria & 95 & 19.0 \\
Sexual symptoms & 236 & 47.2 \\
Vaginal dryness/itching/burning & 155 & 31.0 \\
Dyspareunia & 105 & 21.0 \\
Loss of libido & 204 & 40.8 \\
Postmenopausal bleeding & 16 & 3.2 \\
Genital prolapse & 23 & 4.6 \\
\hline UTI: Urinary tract infection & &
\end{tabular}

UTI: Urinary tract infection

study, Kumar et $\mathrm{al}^{10}$ reported $78 \%$ women had psychosomatic symptoms. Among the psychosomatic symptoms, the commonest complaint was muscle and joint pain $(73.8 \%)$. Muscle and joint pain was the commonest complaint observed in most studies on Indian rural postmenopausal women (40.5-86\%). ${ }^{6-11}$ A similar observation was noted in Indian urban women (45.8-85.7\%). ${ }^{12-14}$ Majority of Asian and African women also complained of muscle and joint pain. ${ }^{3,4,22,24}$

The next common complaint described by majority of postmenopausal women was easy fatiguability $(67.8 \%)$. The frequency of fatiguability in Indian rural postmenopausal women ranged from 40.1 to $89.1 \%{ }^{7-9,14,16,18}$ Similar range of frequency was noted in Indian urban women (40.4-74.3\%). ${ }^{13,14,20}$ About 67.1 to $80 \%$ of Asian and African postmenopausal women described excessive physical and mental exhaustion. Borker et $\mathrm{al}^{9}$ found depression and irritability to be the commonest complaint $(90.7 \%)$. In the present study, low mood was found in $21 \%$ women, which was comparable with other studies $(24.7-44 \%){ }^{11,16,18,19}$ Irritability was observed in $42.2 \%$ women in our study and 17 to $74.6 \%$ women in other studies. ${ }^{11,14,16,18,19}$ In the present study, sleep disturbances were noted in $43.4 \%$ women. This was similar to the observation in several other studies (34-62.7\%). ${ }^{6,8,11,16,18}$ In the present study, $32.2 \%$ women complained of decrease in concentration and $31 \%$ complained of poor memory. In 
the study by Dasgupta and Ray, ${ }^{14}$ a higher percentage of women complained of decreased concentration (68.2\%) and poor memory (81.7\%).

In the present study, the frequency of vasomotor symptoms was $55.8 \%$ and was found next common to psychosomatic symptoms. However, Aaron et al, ${ }^{16}$ Dutta et $\mathrm{al}^{19}$ and Leena and Varghese ${ }^{15}$ found hot flushes and night sweats to be the commonest symptoms in their studies. The frequency of hot flushes was $51.2 \%$ in the present study and 15.6 to $78.2 \%$ in other studies on rural women. ${ }^{6,8,14-16,18}$ The frequency of night sweats was $44.2 \%$ in the present study and ranged from 38 to $62.7 \%$ of rural women in other studies.,14-16,18 The frequency of hot flushes and night sweats in Indian urban postmenopausal women ranged from 38.2 to $80.9 \%{ }^{13,14,20}$ Sharma et al, ${ }^{20}$ Kaulagekar, $^{12}$ and Satpathy ${ }^{13}$ found vasomotor symptoms as the commonest complaint of Indian urban women. Even though psychosomatic symptoms were the commonest symptoms found in Asian and African women, hot flushes and night sweats were found in a higher frequency than in most of the Indian studies. $2,3,21,22,24$

In the present study, $35.2 \%$ women had one or more urinary complaints. Stress incontinence was observed in $14.2 \%$ women in the present study. The frequency of stress incontinence observed in other studies was 21.9 to $38.8 \%{ }^{6,8,16,24}$ In the present study, urgency was noted in $21.4 \%$ of women. Increased frequency of micturition was noted in $29 \%$ of women. Other studies have reported urgency and increased frequency of micturition in 4 to $18 \%$ and 5.8 to $17 \%$ women respectively. ${ }^{6,11,16,19}$ In the present study, $47.2 \%$ women had one or more sexual disturbances. The incidence of sexual symptoms was 6.4 to $47.2 \%$ in other studies. $3,7,10$

About $31 \%$ women complained of vaginal dryness, itching, or burning sensation in the vagina; $21 \%$ women complained of dyspareunia; $40.8 \%$ of women complained of loss of libido. In other studies, the frequency of loss of libido observed was highly variable (6-94.3\%). ${ }^{4,6,9-}$ $12,14,16,18,24$ This variability may be because women may not be forthcoming to discuss about sexual symptoms. Most women attributed loss of libido to age, dyspareunia, vaginal dryness, lack of privacy, presence of grown up children, household priorities, and other health issues. Most women were reluctant to discuss sexual symptoms and approach medical treatment.

In our study, the incidence of genital prolapse was $4.6 \%$ and postmenopausal bleeding was reported by $3.2 \%$ women. The incidence of postmenopausal bleeding (14.4-29.8\%) and genital prolapse (20.6-23.7\%) in other studies was comparatively higher than in the present study. ${ }^{2,4,14}$
In the present study, $68.4 \%$ women had positive attitude toward menopause; $12.2 \%$ women had negative attitude and $19.4 \%$ of women were indifferent to menopause. In the study by Aaron et al, 57\% women welcomed menopause. In the study by Leena and Varghese, ${ }^{15} 47 \%$ women accepted menopause as a normal process; $77 \%$ women had positive perceptions and $23 \%$ had negative perceptions. These observations show that although most women accepted menopause, a significant percentage of women found menopause had a negative impact on their life. Freedom from unwanted pregnancies and distressing menstrual complaints may be favorable influences on menopause. However, loss of fertility, associating menopause to ageing, and fear of health issues associated with menopause may have a negative influence.

In our study, all the participants were aware about the occurrence of menopause and its probable age of occurrence. About $33 \%$ of the women were aware that menopause was associated with certain symptoms. Only $27.8 \%$ were aware that there was some form of treatment for their symptoms. Most women reported their symptoms while approaching a doctor for other health problems; $23.2 \%$ had availed treatment in the form of vitamins or mineral supplements, antibiotics, analgesics, physiotherapy, local vaginal ointments / douches. None of them had received HRT. In their study, Leena and Varghese ${ }^{15}$ found that only $19.5 \%$ of symptomatic women approached a doctor for treatment. The probable factors that deter women from approaching a doctor for their symptoms are ignorance about the availability of treatment for their symptoms, accepting the symptoms as normal age-related changes, misconceptions, lack of family support, and fear or shame to discuss their symptoms.

To sum up, we found that the frequency of postmenopausal symptoms is highly variable in different studies. Even though menopause is a physiological process, menopausal symptoms may be multifactorial. Genetic factors, nutrition, sociodemographic factors, lifestyle, cultural factors, awareness and understanding of health issues, attitude toward health, and access to health care services can influence the type, frequency, and severity of symptoms.

Our study has few limitations. In our study, we have not objectively measured the magnitude or severity of symptoms. The study depends on the attitude of the participants to answer. Participant bias can influence the reliability of answers. Comparative studies have not used uniform techniques for assessing the symptoms. The advantage of this study is that such community-based studies help us to understand the nature and extent of problems faced by the women in the community level. This knowledge helps to have a targeted approach toward the needs of the local postmenopausal women. 


\section{CONCLUSION}

The present study shows that the average age of menopause in our region was comparable with that of other Indian women. Majority of women had one or more symptoms, the commonest being psychosomatic. Even though majority of the women coped up with menopause without significant effect on the quality of life, a sizeable group of women found menopause distressing. Attitude and perception of menopause depend on awareness and utilization of health services. Creating awareness, allaying fear, anxiety, and misconceptions about menopause, and appropriate counseling can change the negative perceptions of women toward menopause. Educating public through health camps, social media, and utilizing health care workers at grassroots level can bring betterment in quality of life and health care seeking attitude of rural postmenopausal women. Pooled data from communitybased studies can be used in formulating strategies to focus on the demand-based needs of postmenopausal women at a larger scale. This can be utilized for planning health programs to improve the quality of life of postmenopausal women.

\section{CLINICAL SIGNIFICANCE}

Menopause is an important transitional phase of life in all women. The waning ovarian hormone level causes several symptoms, some of which can be distressing to some women. Age and symptoms of menopause are influenced by several factors. Attitude and perception of women toward menopause reflect the awareness and health care accessibility in the community. Creating awareness of menopausal symptoms can improve utilization of health services and the quality of life of postmenopausal women.

\section{REFERENCES}

1. World Health Organization Scientific Group. Research on the menopause in the 1990s. WHO Technical Services Department series no. 866. Geneva, Switzerland: WHO; 1996.

2. Ozumba BC, Obi SN, Obikili E, Waboso P. Age, symptoms and perception of menopause among Nigerian women. J Obstet Gynecol Ind 2004 Nov-Dec;54(6):575-578.

3. Rahman SA, Zainudin SR, Mun VL. Assessment of menopausal symptoms using modified Menopause Rating Scale (MRS) among middle age women in Kuching, Sarawak, Malaysia. Asia Pac Fam Med 2010 Feb;9(1):5-10.

4. Marahatta R. Study of menopausal symptoms among peri and postmenopausal women attending NMCTH. Nepal Med Coll J 2012 Sep;14(3):251-255.

5. Baber RJ. East is east and west is west: perspectives on the menopause in Asia and the west. Climacteric 2014 Feb;17(1):23-28.

6. Avin Alva BR, Chethan TK. A study to assess the average age of menopause and menopause associated symptoms among rural women in Mangalore, Karnataka. Ntl J Community Med 2016 May;7(5):404-408.

7. Geetha R, Parida LP. Prevalence of menopausal problems and the strategies adopted by women to prevent them. Int J Sci Res 2015 Apr;4(4):790-795.

8. Nayak G, Kamath A, Kumar P, Rao A. A study of quality of life among perimenopausal women in selected coastal areas of Karnataka, India. J Midlife Health 2012 Jul-Dec;3(2):71-75.

9. Borker SA, Venugopalan PP, Bhat SN. Study of menopausal symptoms, and perceptions about menopause among women at a rural community in Kerala. J Midlife Health 2013 JulSep;4(3):182-187.

10. Kumar R, Nawaz AS, Holyachi SK, Rao V. A study of quality of life among peri-menopausal women in a rural field practice area of a medical college in Karnataka. Ntl J Community Med 2016 Mar;7(3):160-164.

11. Sarkar A, Pithadia P, Goswami K, Bhavsar S, Makwana NR, Yadav S, Parmar DV. A study on health profile of postmenopausal women in Jamnagar district, Gujarat. J Res Med Den Sci 2014;2(2):25-29.

12. Kaulagekar A. Age of menopause and menopausal symptoms among urban women in Pune, Maharashtra. J Obstet Gynecol India 2011 Jun;61(3):323-326.

13. Satpathy M. A study on the knowledge and awareness about menopause among middle aged women from Western Odisha. Int J Sci Res 2016 Juk;5(7):1759-1761.

14. Dasgupta D, Ray S. Menopausal problems among rural and urban. Women from Eastern India. J Soc Health Sci 2009;3(1):20-33.

15. Leena AJ, Varghese AP. Prevalence of menopausal symptoms and perceptions about menopause among postmenopausal women attending gynaecology OPD at GMC Idukki, India. Int J Reprod Contracept Obstet Gynecol 2017;6(2):413-416.

16. Aaron R, Muliyil J, Abraham S. Medico-social dimensions of menopause: a cross-sectional study from rural south India. Natl Med J India 2002 Jan-Feb;15(1):14-17.

17. Mangal A, Kumar V, Panesar S, Talwar R, Raut D, Singh S. Updated BG Prasad socioeconomic classification, 2014: a commentary. Indian J Public Health 2015;59(1):42-44.

18. Singh A, Pradhan SK. Menopausal symptoms of postmenopausal women in a rural community of Delhi, India: a crosssectional study. J Midlife Health 2014 Jun;5:62-67.

19. Dutta R, Dcruze L, Anuradha R, Rao S, Rashmi MR. Population based study on the menopausal symptoms in a rural area of Tamil Nadu, India. J Clin Diagn Res 2012 May;6(4):597-601.

20. Sharma S, Tandon V, Mahajan A. Menopausal symptoms in urban women. J K Sci 2007;9(1):13-17.

21. Yahya S, Rehan N. Age pattern and symptoms of menopause among rural women of Lahore. J Ayub Med Coll Abbottabad 2002 Jul-Sep;14(3):9-12.

22. Nusrat N, Nishat Z, Gulfareen H, Aftab M, Asia N. Knowledge, attitude and experience of menopause. J Ayub Med Coll Abbottabad 2008 Jan-Mar;20(1):56-59.

23. Kriplani A, Banerjee K. An overview of age of onset of menopause in northern India. Maturitas 2005 Nov-Dec;52(3-4): 199-204.

24. Alizadeh M, Sayyah-Melli M, Ebrahimi H, Shishavan MK, Rahmani F. Social determinants and reproductive factors of the menopausal symptoms among women in Tabriz-Iran. Soc Determin Health 2015;1(1):2-8. 